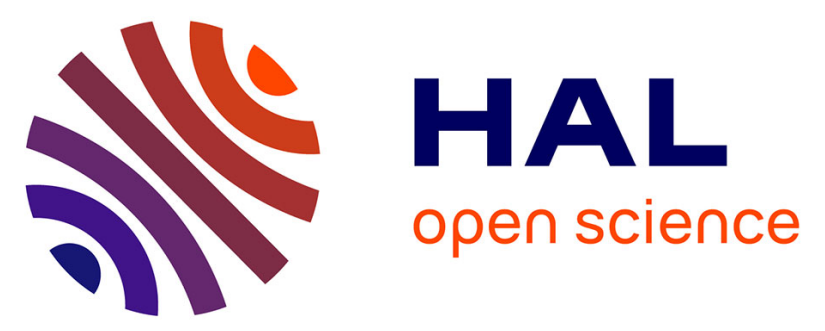

\title{
Research on Social Risk Evolution and Control of the Large Hydraulic Project Construction Based on Society Burning Theory
}

Bo Wang, Dechun Huang, Haiyan Li, Chang Zheng Zhang, Zheng Qi He

\section{- To cite this version:}

Bo Wang, Dechun Huang, Haiyan Li, Chang Zheng Zhang, Zheng Qi He. Research on Social Risk Evolution and Control of the Large Hydraulic Project Construction Based on Society Burning Theory. 8th International Conference on Computer and Computing Technologies in Agriculture (CCTA), Sep 2014, Beijing, China. pp.359-370, 10.1007/978-3-319-19620-6_41 . hal-01420252

HAL Id: hal-01420252

https://hal.inria.fr/hal-01420252

Submitted on 20 Dec 2016

HAL is a multi-disciplinary open access archive for the deposit and dissemination of scientific research documents, whether they are published or not. The documents may come from teaching and research institutions in France or abroad, or from public or private research centers.
L'archive ouverte pluridisciplinaire HAL, est destinée au dépôt et à la diffusion de documents scientifiques de niveau recherche, publiés ou non, émanant des établissements d'enseignement et de recherche français ou étrangers, des laboratoires publics ou privés.

\section{(ㄷ)(i)}

Distributed under a Creative Commons Attribution| 4.0 International License 


\title{
Research on Social Risk Evolution and control of the Large Hydraulic Project Construction Based on Society Burning Theory*
}

\author{
Bo Wang ${ }^{1,2, a}$, Dechun Huang ${ }^{1,2, b}$, Haiyan $\mathrm{Li}^{3, \mathrm{c}}$, \\ Changzheng Zhang ${ }^{1,2, \mathrm{~d}}$, Zhengqi He${ }^{1,2, \mathrm{~d}}$ \\ ${ }^{1}$ Business School of Hohai University, Nanjing 211100, China; ${ }^{2}$ Industrial Economics Institute \\ of HHU, Nanjing 211100, China; ${ }^{3}$ College of Mathematics and Information Science, Beifang \\ University of Nationalities, Yinchuan 750021, China \\ asensitivebaby@126.com, bhuangdechun66@163.com, ${ }^{\mathrm{c} l i h a i y a n m a t h @ 163 . c o m, ~}$ \\ dhhu2007@126.com, ${ }^{\mathrm{e}} 751952329 @$ qq.com
}

\begin{abstract}
The construction of large hydraulic project improves the efficiency of water using and it will bring the social risk which has the dynamic evolution characteristic. In order to research the evolution process of social risk of large hydraulic project construction, a social risk evolution model is established based on society burning theory to depict the risk dynamic evolutionary process quantitatively. At last, an early warning control model is constructed. At the same time, the rational comprehensive mechanism of interests, the informational processing communication mechanism and the comprehensive emergency control system are put forward to reduce the risk level from the point of view of guarding and controlling the social risk.
\end{abstract}

Keywords: large hydraulic project, society burning theory, social risk evolution model, risk control

\section{Introduction}

In order to solve the urgent needs for social and economic development, China constructs a number of large hydraulic projects, such as the Three Gorges Project, the Gezhou Dam and South-North Water Transfer Project which are under construction. The successful implementation of major projects could bring profound influence in politics and economics [1].However, there are some complex issues need to solve in the process of construction and operation; even improper handling way may lead to social conflicts. At present, China under the rapid social transformation, all kinds of social contradictions and problems occur frequently because of rapid social changes. Social risks associated with the social structure changes bring a major challenge to maintain social stability.

At present, academic literatures in this field focus, mainly, on the social impact assessment, social risk and stability of hydraulic project. D.M Rosenberg [2-3]

\footnotetext{
* Fund supported: Special Program For Key Program for International S\&T Cooperation Projects (2012DFA60830)
} 
considers the problems of economic and environmental benefits of large hydraulic project construction respectively. Fu Peng gave a quantitative research through establishing an index system on hydraulic conservancy project [4]. The researches about social risk of water conservancy project construction mainly focus on immigrant. Li Hua and Jiang Hualin[5] pointed out the social integration of immigrants is at the heart content of Three Gorges Project on Migration and social stability. Chen Yan analyzed the social risk from immigrants' resettlement and made qualitative analysis according to the risk Analysis Questionnaire [6].Yang Fan and Yu Jianxing analyzed the risk factors for resettlement project and applied the fuzzy mathematics method to make a risk analysis and the quantitative analysis [7]. In addition, Zhang Jie and Wang Huimin[8] analyzed the social risks brought about by South-North Water Transfer Project from the point of view of risk society theory. Yu Wenxue discussed social problem and countermeasure for construction of water conservancy projects from the perspective of the history and development [9].Judging from combing the literature, we find out the current studies of the risks and social influences, triggered by water conservancy project construction, mainly focus on static assessment and lack of dynamic and systematic research. However, construction of water conservancy is system engineering. The risk produced from that is a dynamic evolutionary process which gradually accumulated until the outbreak. How to research the social risk evolution process of large hydraulic project from the point views of the risk evolution, we should use the society burning theory as an important tool and method. Fan Zemeng and Niu Wenyuan developed a novel mechanism model for controlling the stability of the social system based on society burning theory. They saw the stability of the social system as the balance of four forces from the systematic perspective [10].

In this paper, we introduce the force balance principle and concept of energy and seen the social risk evolution of large hydraulic project as the acceleration proceeds of object movement. Then, a social risk evolution model, based on the framework of society burning theory, was developed. According to this model, we give a quantitative description with respect to the social risk evolutionary progress and construct the risk control model which helps us to study how to guard and control the social risk. The workings in this paper maybe offer a reference for quantitatively analysis and control the social risk of large hydraulic project.

\section{Definition of social risk and theoretical foundation}




\subsection{Definition of social risk about large hydraulic project}

Risk is loss of uncertainty which throughout the development of the society, it always could not be eliminated [11]. In the progress of large hydraulic project construction, there are many stakeholders involved, moreover, all the factors of large hydraulic project construction influence with each other. All of these result in particularity social risks, so we should make a definition for social risk. Feng Biyang deemed that the social risk is social losses uncertainty from abroad view of definition; at the same time, social risk refers to a risk like political risk, economic risk, cultural risk, financial risk and decision-making risk [12]. For the risk of large hydraulic project, the definition of that means the uncertainty of loss about politics, engineering, environment and economy. Associated with that, we called the narrow definition of social risk of large hydraulic project is a possibility which could result in the unrest and instability of the local community. The main reasons give rise to social risk is the contradictions produced by compensation and allocation of large hydraulic project under different time and space between people and nature. In this paper, our research focuses on the narrow definition of social risk.

\subsection{Theoretical basis for social risk evolution analysis of large hydraulic project}

The society burning theory likens the social disorder, instability and turmoil to burning material. This theory shows disharmony between people, people and nature will bring the negative influences (burning material), when these influences accumulated to a certain degree, it will form a certain population density and geographical spatial scale under wrong public opinion (Oxidizer); at the same time, it will make the society out-of-balance, disorder so far as to breakdown(Ignition temperature)[13]. On the other hand, construction of large hydraulic project involves so many people and interest group, uneven interest compensation and redistribution can lead to social conflicts and disharmony easily. It can produce underlying social risk because of "burning material". So, on the one hand, we can regard all the social conflicts and unstable factors. The spread of rumors between people and people can be seen as the "Oxidizer" which accelerate the social contradictions and make the risk of instability gathered. When the contradictions become the common interest expression, it will form a certain population density and geographical spatial scale, the social risk level will close in on the critical range of social unrest. Under the incitation of the emergent mass incident, it will emerge the "Ignition temperature" of social unrest which may result in the "society burning" if the influences exceed the maximum safe bearing capacity. So, we draw a conclusion that the society burning theory gives a reasonable tool for analysis the risk evolution of large hydraulic project. 


\section{Model of society risk evolution of large hydraulic project based on society burning theory}

\subsection{Idea for model building}

Fan Zemeng and Niu Wenyuan [14] regard emergencies as the process of the material movement from starting to stopping. We consider this idea accords with research on the social risk evolution. So, social conflicts, risk material, the volume of social contradictions and risk material determine the dynamic evolution of social risk. Social risk of large hydraulic project is a process of accumulation, acceleration and breaking out. Therefore, we introduce the object quality, acceleration and kinetic energy with analog modeling method for social risk evolution.

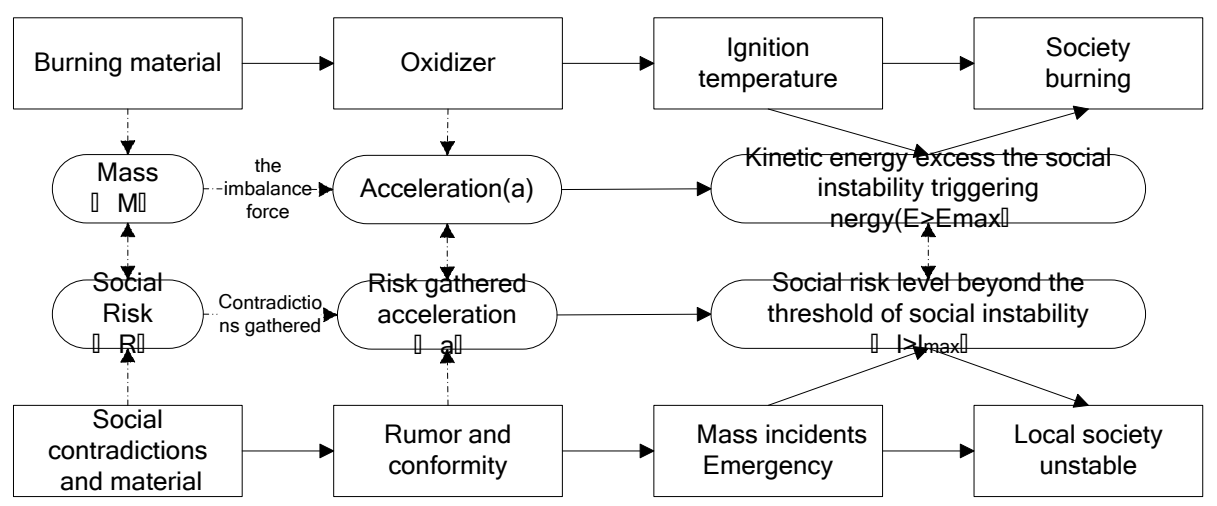

Fig.1. Social risk evolutionary model of analogy modeling ideas

\subsection{Model assumption}

We assume that the model satisfies the following assumptions:

(H1): The stability of the local community of large hydraulic project construction depends on the balance between $\vec{F}_{N}$ and $\vec{F}_{P}$. Where, $\vec{F}_{P}$ denotes the synergy forces which power depends on the ability of assure large hydraulic project local social stability. $\vec{F}_{N}$ denotes the impact force which could lead to social instability which power depends on the damage by large hydraulic project construction.

(H2): The amount of society contradictions and social risk materials $M_{B}(t)$ is a dynamic variable over time. The direction of movement depends on the direction and power of the resultant force between $\vec{F}_{N}$ and $\vec{F}_{P}$.The power of the resultant force can be measured in a period.

(H3): In the process of large hydraulic project construction, social risk level can be reflected by the amount of society contradictions and social risk materials accurately. 
(H4): When $\vec{F}_{N}>\vec{F}_{P}$, social risk will close in on critical range of social unrest, at this time, we need social control force $\vec{F}_{C}$ to maintain social stability, which power depends on emergency mechanism and safeguard stability in large hydraulic project construction.

\subsection{Representation model}

Newton's laws of classical kinematics believe the state of motion of the object is determined by its balance of the force. When the object showed accelerated motion, its direction of motion is determined by the direction of the resultant force. Social risk has dynamic evolutionary feature. We denote $M_{B}(t)$ is social contradictions and risk material and $\overrightarrow{a_{t}}$ is "oxidizer" at time $t$, so we get the acceleration model of social risk evolution.

$$
\vec{a}_{t}=\left(\vec{F}_{N}-\vec{F}_{P}\right) / M_{B}(t)=\frac{\left(\vec{f}\left(y_{1}, y_{2}, \cdots, y_{i}, t\right)-\vec{h}\left(z_{1}, z_{2}, \cdots z_{j}, t\right)\right)}{m\left(x_{1}, x_{2}, \cdots x_{k}, t\right)}
$$

Where $\vec{F}_{N}-\vec{F}_{P}$ denotes the resultant force, $M_{B}(t)=m\left(x_{1}, x_{2}, \cdots x_{k}, t\right)$ is social contradictions and risk material at time $t$. Here $\left(x_{1}, x_{2}, \cdots x_{k}, t\right)$ is a vector of social contradictions and risk material. We denote the impact force is $\vec{F}_{N}=f\left(y_{1}, y_{2}, \cdots, y_{i}, t\right)$, here $\left(y_{1}, y_{2}, \cdots, y_{i}, t\right)$ is a negative factors vector of large hydraulic project construction; $\vec{F}_{P}=h\left(z_{1}, z_{2}, \cdots z_{j}, t\right)$ represents synergy forces, here $\left(z_{1}, z_{2}, \cdots z_{j}, t\right)$ is a vector of large hydraulic project construction for compensation.

We denote the initial velocity of society contradictions and social risk materials is $\vec{V}_{0}$, the model of the kinetic energy generates at time $t$ by $M_{B}(t)$ as follow:

$$
\begin{gathered}
\vec{V}_{t}=\vec{V}_{0}+\int_{t_{0}}^{t} \vec{a}_{t} d t \\
E(t)=M_{B}(t) \cdot \vec{V}_{t}^{2} / 2=M_{B}(t) \cdot\left(\vec{V}_{0}+\int_{t_{0}}^{t} \vec{a}_{t} d t\right)^{2} / 2
\end{gathered}
$$

Here, we define the maximum bearing capacity of local society as the triggering energy of social instability from stable to unstable.

$$
E_{\max }=S\left(w_{1}, w_{2}, \cdots w_{s}\right)
$$

Here, $\left(w_{1}, w_{2}, \cdots w_{s}\right)$ represent a vector of society development which level depends on the system of laws, military and police, the wealth of society, emergency security system etc.

When the social risk level will close in on the critical range of social unrest, social control force contributes to lower levels of social risk. So, we have the relation among 
"fire extinguishing agent" $\overrightarrow{a_{C}}$, fire extinguishing speed $\vec{V}_{C, t}$ and the social control energy $E_{C}(t)$.

$$
\begin{gathered}
\overrightarrow{a_{C}}=\overrightarrow{F_{C}} / M_{B}(t)=\frac{\vec{g}\left(c_{1}, c_{2}, \cdots, c_{l}, t\right)}{m\left(x_{1}, x_{2}, \cdots x_{k}, t\right)} \\
\vec{V}_{C, t}=\vec{V}_{C, 0}+\int_{t}^{t_{4}} \overrightarrow{a_{c}} d t \\
E_{C}(t)=M_{B}(t) * \vec{V}_{C, t}^{2} / 2=M_{B}(t) *\left(\vec{V}_{C, 0}+\int_{t}^{t_{4}} \overrightarrow{a_{c}} d t\right)^{2} / 2
\end{gathered}
$$

Where $\overrightarrow{V_{C, 0}}$ is the initial speed of social control force, opposite direction to $\vec{V}_{t}$, and the direction and magnitude of "fire extinguishing agent" $\vec{a}_{C}$ is decided by the social control force $\vec{F}_{C}$.

\section{Social risk evolution of large hydraulic project}

The society development direction of large hydraulic project depends on the balance effect between impact force $\vec{F}_{N}$ and synergy force $\vec{F}_{P}$. Synergistic effect will promote the society development and vulnerable effect will result in the possibility of social unrest. For convenience, we denote magnitude of impact the force and synergy force of large hydraulic project like $\left|\vec{F}_{N}\right|$ and $\left|\vec{F}_{P}\right|$ respectively.

\subsection{Social risk evolution dominated by synergy effects}

(1) when $\left|\vec{F}_{N}\right| \cong\left|\vec{F}_{P}\right|$, the two forces into balance, the $\left|a_{t}\right| \cong 0$ and $\left|V_{t}\right| \cong 0$. The negative effects from large hydraulic project construction into balance with positive effects from compensation and investment of project construction. So the amount of society contradictions and social risk materials $M_{B}(t)$ and social risk $l(t)$ at lower levels. Kinetic energy $E(t)=M_{B} \vec{V}_{0}^{2} / 2$ produced by $M_{B}(t)$ is lower than triggering energy; the stable state will sustain stability and balance, see fig.2. 


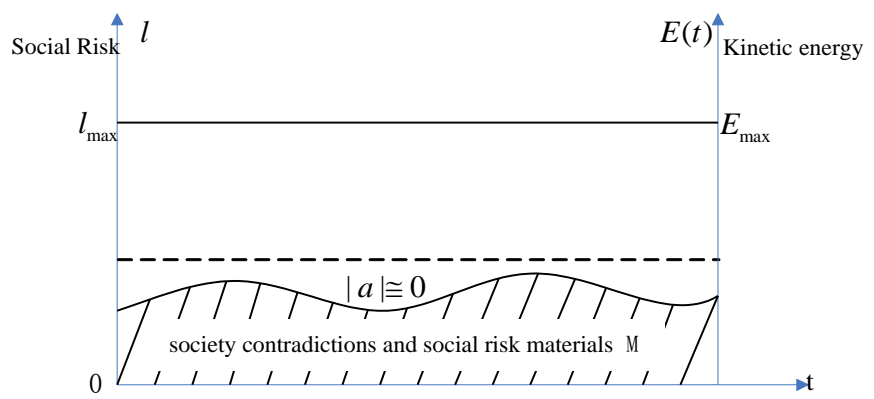

Fig. 2. Social risk evolutionary trend when $\left|\mathrm{F}_{\mathrm{N}}\right| \cong\left|\mathrm{F}_{\mathrm{P}}\right|$

(2)When $\left|\vec{F}_{N}\right|<\left|\vec{F}_{P}\right|$, interests compensation makes the positive effects greater than negative effect in large hydraulic project construction process. The acceleration of social contradictions and risk material $\left|a_{t}\right|<0$ has the same direction with $\left|\vec{F}_{P}\right|$.This means that the amount of society contradictions and social risk materials $M_{B}(t)$ decreases gradually and social risk $l(t)$ has a lower level. The velocity of social contradictions and risk material $\vec{V}_{t}$ is less than initial velocity $\vec{V}_{0}, \vec{V}_{t}$ has the opposite direction with $\vec{V}_{0}$. At the same time, the kinetic energy $E(t)$ reduces gradually, see fig. 3 .

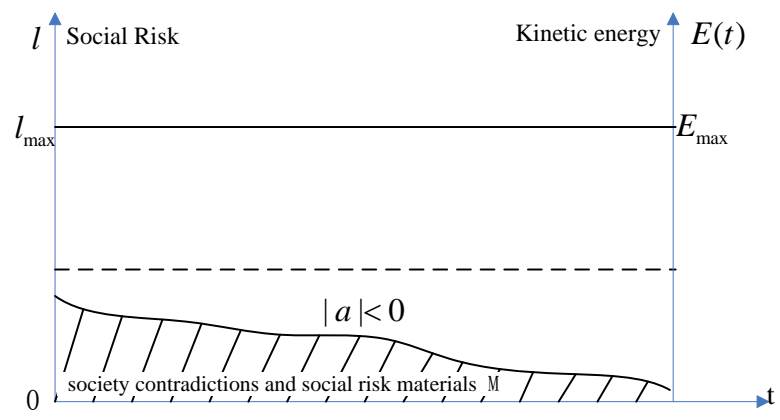

Fig. 3. Social risk evolutionary trend when $\left|\mathrm{F}_{\mathrm{N}}\right|<\left|\mathrm{F}_{\mathrm{P}}\right|$

\subsection{Social risk evolution dominated by vulnerability effects}

Social risk evolution is a process which includes risk production, development and diffusion until calm. Fu Yun(2008) give a model which describes the group unexpected incidents as four stages :latent, development, climax, attenuation. With the accumulation of social contradictions and risk material, the potential social risks will show the different levels in different stages. Therefore, we can divide social risk evolution into four stages, like the initial stage, acceleration stage, explosion stage and Calm stage. 


\subsubsection{Social risk evolution with none-control force}

At the initial stage of large hydraulic project construction process, $t \in\left(t_{0}, t_{1}\right)$. There is

a balance between $\vec{F}_{N}$ and $\vec{F}_{P}$ and the amount of society contradictions and social risk materials $M_{B}(t)$ is small and social risk has a lower level. This mainly thanks to the society contradictions and risks coordinate with reasonable investor compensation scheme, such as environmental protection, immigration resettlement, fund compensation and job placement etc., so the social risk lie at a lower level.

At the acceleration stage, $t \in\left(t_{1}, t_{2}\right)$, the policy, fund and other compensation measure will show up same shortages, such as the investigation discovered that some immigrants recognize their life quality lower and the final-period support for the migrants failed to reach its budget targets[15]. There is going to emerge some phenomenon like "industry hollowness", "return of immigrant", "psychosocial environment fragility" and conformity behavior increasing etc [16]. That will make a scale effect of risks communication under inaccurate reports and spreading of rumors. At this stage, the acceleration of society contradictions and social risk materials $\left|a_{t}\right|>0$, which has the same direction with $\vec{F}_{N} \cdot M_{B}(t)$ move with $\vec{V}_{t}$ and its kinetic energy will close in on maximum bearing capacity. At the same time, the social risk level $l(t)$ will accelerate to $l_{\max }$. Social risks break out intensively ignited by mass disturbance. If we cannot take regulatory action, i.e. none-control force $\vec{F}_{C}$, the social level will over the $l_{\max }$, the local society will face the possibility of disorder and instability. See Fig.4.

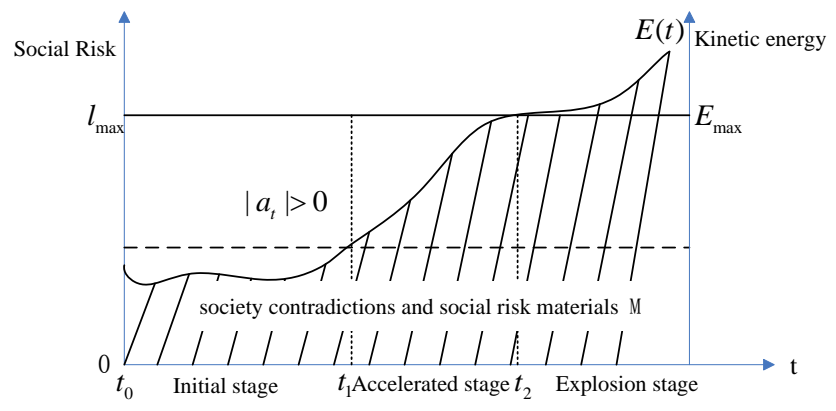

Fig. 4. Social risk evolutionary trend with none-control force $\vec{F}_{C}$

\subsubsection{Social risk evolution with control force}

In the process of large hydraulic project construction, social risk at a lower level under social development dominated by synergy effects and the possibility of disorder is small. When social risk level is close to the $l_{\text {max }}$, the local society maybe comes up instability. Quantities of social conflicts, disorder action and public order cases go 
up. In this situation, disclose the information, emergency measures were carried out until society restore stability and normal order as soon as possible.

Seen as fig. 5 , when $t \in\left(t_{2}, t^{*}\right)$, the mount of society contradictions and social risk materials gathers with acceleration $\left|a_{t}\right|>0$ and social force $\vec{F}_{C}$ will reduce the $M_{B}(t)$ with acceleration $\vec{a}_{c}$. Social control energy $E_{C}(t)$ is increasing and social risk level will lower. There is a peak value in this stage about $l(t)$ and $E(t)$ at time $t^{*}$.In $t \in\left(t^{*}, t_{3}\right)$, the social risk level will reduce under $\vec{F}_{C}$, the amount of $M_{B}(t)$ saw the area of the dotted line form in fig. 5 and when $t \in\left(t_{3}, t_{4}\right)$, the social risk level will lower at the reasonable range and society order can be controlled.

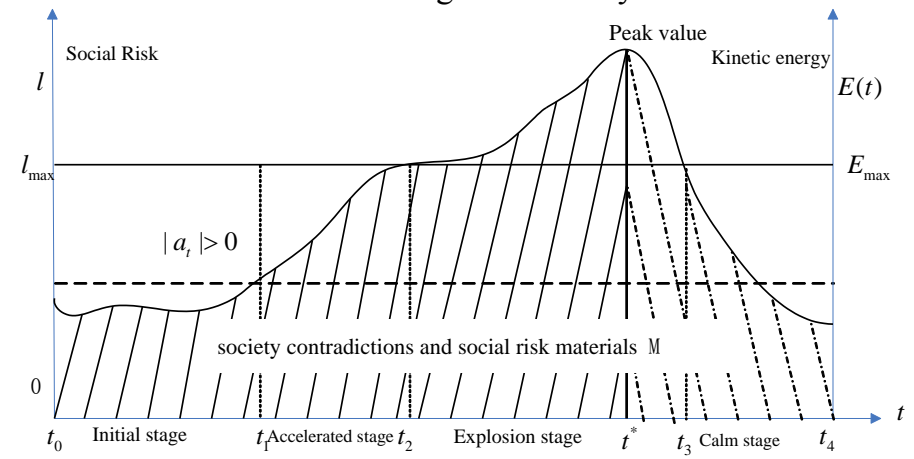

Fig. 5. Social risk evolutionary trend with control force $\vec{F}_{C}$

\section{Social risk control of large hydraulic project construction}

\subsection{Social risk warning mode of large hydraulic project}

Social risk warning is an important link for cut off the risk spreading. Social risk will often breakout suddenly, but the emergence and development of risk is a process. So only build the early warning mechanism, can we prevent loss from social risk [17].When social risk level approach and exceeds the risk threshold, the local society will be in a critical state of disorder and $E(t)$ approach $E_{\max }$ too. At the stage $\left(t_{1}, t_{2}\right)$, the comprehensive risk warning system takes an important role in identifying risks and lowering the possibility of society instability and disorder. At the time $t$, under the effect of resultant force between $\left(\vec{F}_{N}-\vec{F}_{p}\right)$ and $\vec{F}_{C}$. Correspondingly, $\left|\vec{a}_{t}\right|<\left|\vec{a}_{\mathrm{C}, t}\right|$ and $\left|\vec{V}_{t}\right|<\left|\vec{V}_{C, t}\right|$. These changes are shown in Fig. 6. 


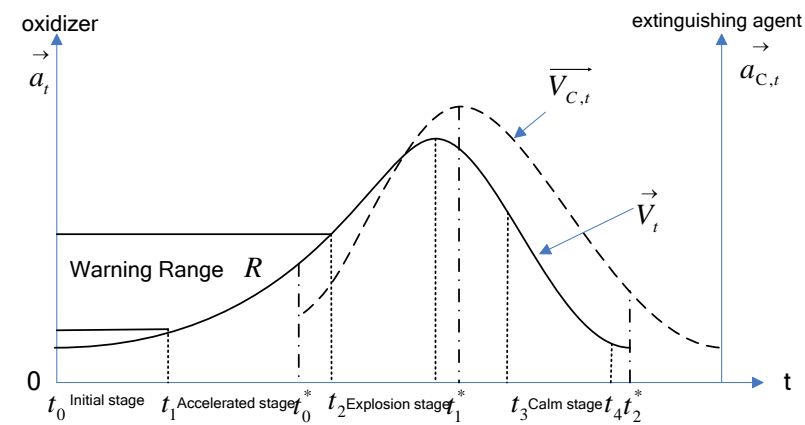

Fig.6. Social risk warning control curve of large hydraulic project construction

In figure 6 , the full line shows the velocity of social risk and dotted line shows the velocity of social control force. Here $t_{0}^{*}$ is the initial time of social control force involving, $\left(t_{0}^{*}, t_{1}^{*}\right)$ and $\left(t_{1}^{*}, t_{2}^{*}\right)$ are accelerated stage and reducing stage of "fire extinguishing" velocity $\vec{V}_{C, t} \cdot \vec{V}_{C, t}$ will reach the peak value at $t_{1}^{*}$. The area $R$ that $\vec{V}_{t}$ curve connects with the ordinate of $\vec{a}_{t}$ named warning range. At initial stage, here $\left|\overrightarrow{a_{t}}\right|>\left|\vec{a}_{\mathrm{C}, t}\right|$, social risk is in the spreading state. In $\left(t_{0}^{*}, t_{1}^{*}\right)$ stage, the power of social control force increase gradually, accordingly $\left|\vec{a}_{t}\right|<\left|\overrightarrow{a_{\mathrm{C}, t}}\right|$ and $\left|\vec{V}_{t}\right|<\left|\vec{V}_{C, t}\right|$. Social risk level and velocity will lower with time.

\subsection{Measures of social risk prevention and control of large hydraulic project construction}

\section{(1) Establishing reasonable benefits compensation mechanism}

The reasonable benefits compensation mechanism and measures can reduce the society contradictions and social risk materials. Large hydraulic project construction involves the extensive interest groups and has the widespread influence. Project construction leads to social interest recombined and distribution pattern changed. But beyond that, definition of interest groups and the strength of compensation also affect the "synergy effects". For a long time, definition of an interest group and compensation is planned by the government, so that also lack of the actual investigation. But policy carry out maybe neglect the interested parties' real demand. So we must consider the different group and overall planning by different level and region. Taking measures according to local conditions and adjusting policy is the necessary choice. At the same time, we should build the benefits and ecology compensation mechanism by steps and stages.

(2)Establishing information processing and communication mechanism 
The one way to control the spread of social risk is controlling the acceleration of society contradictions and reducing social risk materials. The "oxidizer" in society burning theory can appear public opinions and make the add fuel to the flame function [18].The construction of large hydraulic project construction often makes the folks feel anxious, group psychology. These factors will make the social psychological environment fragile and fake information spreading. So we need to establish the information processing mechanism. On the one hand, we should build the public opinion monitor mechanism for identifying information and publish to public, which can hold back the folk information from source. On the other hand, when the social psychology no way to appealed, feelings of anxiety and inadequacy will spread in the chain of acquaintances and form the scale effect in the short period. So, we should build the multiple communication mechanism between government and the grassroots and build mutual trust.

\section{(3) Building perfect social emergency control system}

As the main measures for social risk control, the social emergency control system provides an important guarantee for risk control. The social control force decides the efficiency of risk control. For the past few years, social emergency event, such as SARS and Wenchuan earthquake, reflects the shortage of the social emergency control system. So, first of all, we should strengthen the construction of social emergency ability and change the oneness and limitations of previous emergency measures. At the same time, we should build the multi-departments interaction mechanism and information sharing mechanism to guarantee the timeliness of emergency control measures. Secondly, mass disturbances are the triggered factor has the sudden and dynamic feature so that we should take the dynamic action for it [19]. At last, we need to guide and encourage non-governmental organization and the public welfare social group to take part in building the social emergency control system. Meanwhile, we should play the functions of civil organizations to guide public opinion reasonably thereby reducing the social risk level.

\section{Conclusions}

Large hydraulic project construction brings the economic effectiveness, but it results in the social risk which has the evolutionary character. In this paper, we build the social risk evolution model based on society burning theory and analyze the evolutionary process from the balance between synergy effects and vulnerability effects. By quantitative description, we draw conclusions to control the social risk and avoid risk distorting and diffusion. First of all, establishing the perfectible benefits compensation mechanism to reduce the amount of society contradictions and social risk materials; secondly, establishing a good information processing and communication mechanism; at last, building the comprehensive social emergency control system to improve level of social risk emergency security . 
In this paper, we describe the social risk evolution process and propose control measures according to social risk evolution mode. But how to measure and calculate the variables of the model and make the quantitative calculation is another work in future research.

\section{Acknowledgment}

Funds for this research was provided by Special Program For Key Program for International S\&T Cooperation Projects (2012DFA60830), the National Social Sciences Fund(11BGL088) and the graduate student research innovation project for Jiangsu province university, 2011(CXLX12_0260).

\section{References}

1. Gao Liang, Liu jie. National Key Projects and National Innovation Ability[J]. China Soft Science, 2005, (4):17-22.

2. D.M Rosenberg, R A Bodaly, P J Ushe. Environmental and social impacts of large scale hydro-electric development: who is listening?[J]. Global Environmental hange, 1995,5(2):127-148.

3. D.M. Rosenberg, F. Berkes, R.A. Bodaly, R.E. Hecky, C.A. Kelly, J.W.M. Rudd. Largescale impacts of hydroelectric development [J]. Environmental Review, 1997,(5):27-54.

4. FU Peng, CHEN Kaiqi, XIE Yuebo, ZHANG Duguang. Method for environment impact assessment of hydropower development considering social factors [J]. Journal of Hydraulic Engineering, 2009,40(8):1012-1018.

5. LI Hua, JIANG Hua lin. On Social Amalgamation and Social Stabilization of Three Gorges Project Resettlement[J].Journal of Chongqing University (Social Sciences Edition), 2002,9(2):37-40.

6. Chen Yan, Chen Shaojun and Wang song. Social risk evaluation of reservoir immigrants [J]. Journal of Economics of Water Resources, 2005,3,23(2):62-64

7. Yang Fan, Yu Jianxing. The risk analysis and evaluation of Water conservancy project resettlement work[J].Journal of hydraulic engineering,2005, 36(10) : 1258-1262.

8. Zhang Jie, Wang Huimin. Society risk analysis of South-to-North Water Society[J].Yangtze River,2006,4(2),18-19.

9. Wenxue $\mathrm{Yu}$. Social issues caused by water resources project and Countermeasures [J].Journal of Hohai University,2005,7(4),54-56.

10. Zemeng Liu,Wenyuan Niu.Social stability mechanism model[J].System engineering theory and Practice,2007,(7):69-76.

11.Hu Angang, Wang Lei. A Study of the Measur ement Methods and Exper iences Concerning the Risks from Social $\operatorname{Tr}$ ansition (1993 2004)[J]. Management World, 2006,(6):46-54.

12. Feng Biyang. Social risk: perspective, contents and factor[J]. Tianjin Social Sciences, 2004,(2):72-77.

13. Niu Wenyuan. The Social Physics and the Warning System of China Social Stability [J]. Bulletin of the Chinese Academy of Sciences, 2001,(1):16-20. 
14.Zemeng Liu,Wenyuan Niu,Jifa Gu.Social emergency response model and control pattern analysis[J].China Soft Science,2007,(8),85-92.

15. Huang Dongdong. Can it take root After landing?--investigation and thought about rural migrants placed from the Three Gorges [J].World of survey, 2009,(5):28-30.

16. Sun Yuanming. The Three Gorges Reservoir Area" after the migration period" major social problems analysis of regional social problems reasons and Countermeasures [J].China Soft Science, 2011,(6):24-33.

17.Song Linfei. Social risk warning system design and operation [J]. Journal of Southeast University, 1999,1(1):70-76.

18.Shan Yuefei, Gao Jingfang. Social Physical Interpretation of Reasons for Mass Disturbances: The Introduction of Social Combustion Theory[J]. Journal of Shanghai University of Finance and Economics, 2010,6(12):26-33.

19.Tong Xing, Zhang Haibo. Group events and its governance--further consideration under the integrated framework social risk and public crisis [J].Academic circles, 2008, (2):35-45. 